\title{
MHEALTH APPLICATIONS DEVELOPED BY THE Ministry of HeAlTH FOR PUblic USERS INKSA: a Persuasive Systems Design Evaluation
}

\author{
Asmaa Shati \\ Department of Information Systems, IMSIU University, Riyadh, KSA Department of \\ Information Systems, KKU University, Abha, KSA
}

\begin{abstract}
mHealth applications have shown promise in supporting the delivery of health services in peoples' daily life. Recently, the Ministry of Health in the Kingdom of Saudi Arabia (MOH) has launched several mHealth applications to develop work mechanisms. Our study aimed to identify and understand the design of mHealth apps by classifying their persuasive features using the Persuasive Systems Design (PSD) model and expert evaluation method. This paper presents the distinct persuasive features applied in recent applications launched by MOH for public users called "Sehha \& Mawid" Apps. The results revealed the extensive use of persuasive features; particularly features related to credibility support, dialogue support and primary task support respectively. The implementation and design of social support features were found to be poor; this could be due to the nature of the apps or lack of knowledge from the developers' perspectives. The findings suggest some features that may improve the persuasion for the evaluated apps.
\end{abstract}

\section{KEYWORDS}

Persuasion, mHealth apps, The persuasive systems design model (PSD), MOH, Persuasive features.

\section{INTRODUCTION}

Kingdom of Saudi Arabia is considered one of developing countries that is trying to improve the health sector using recent technologies [14]. Mobile Applications are becoming an increasingly important tool for the delivery of health services in different countries. Recently, mobile health applications have been used as tools for enhancing physical activity and healthy diets [4], sending patients reminders about upcoming appointments, patients and clinician consultation and many other health concerns [6]. Consolvo [4] found that mobile phones are particularly attractive way of delivering health involvements because of several reasons. The most significant reasons are the widespread adoption of phones with increasingly powerful technical capabilities, and people's tendency to carry their phones with them everywhere. Thus, in recent years, many large hospitals have provided various online healthcare services that enable patients to expediently consult with physicians and obtain healthcare services in an online format using mobile health applications [6].

According to Aranda-Jan [2] study "mHealth refers to the use of mobile communication technologies to promote health by supporting healthcare practices, e.g. delivery of healthcare information, or patient observation and provision of care". Mobile Health in the Kingdom of Saudi Arabia is an innovative approach for delivering health services and receiving great attention from the Ministry of Health. MOH has launched various health applications to serve the citizens and employees in KSA. For instance, to facilitate access to virtual medical consultations on 
smartphones (e.g. Sehha App), to book an appointment from the nearest healthcare centers (e.g. Mawid App), to enable its employees to do their HR activities easily (Mawred App), and many other apps of different purposes.

The Internet, mobile, and other current technologies create opportunities for persuasive interaction since users can be reached smartly and services can be delivered easily. OinasKukkonen \& Harjumaa [10] stated that several areas have been existed where persuasive technology could be useful. For instance, healthcare applications may be developed to motivate people toward healthy behavior, postpone or even prevent medical problems and making the economic situation more flexible in public healthcare. So, we believe that the persuasive design of mobile health applications launched by the $\mathrm{MOH}$ in KSA needs to be evaluated using the most comprehensive model such as the PSD model. This model provides a schema for selecting application features and analyzing the persuasion context by addressing the intent (intended change), the event (use, users and the technology) and the strategy (persuasive message and delivery route) accompanying the 28 persuasion features defined by the PSD model. Hence, this study answers the following question: what diversities of persuasive systems' features are utilized in the mHealth apps developed by $\mathrm{MOH}$ ?

Section 2 provides a literature review about persuasive systems design. Section 3 describes the research settings. Section 4 is the main part of this paper and it presents results and discussion. Section 4 concludes our study.

\section{LiTERATURE REVIEW}

\subsection{Persuasive Systems Design}

Persuasion is defined as the process of communication in which a persuader sends a persuasive message to persuade the recipient, intending to influence behavior and/or attitude, while leaving him with the power of decision [3]. Persuasive systems can be defined as "computerized software or information systems designed to reinforce, change or shape attitudes or behaviors or both without using coercion or deception" [10]. According to Oinas-Kukkonen \& Harjumaa [10], persuasive systems may use two types of persuasion either computer-human persuasion or computer-mediated persuasion. The persuader concept is somewhat complex with computerhuman persuasion. Those who adopt the technology are the ones who have the intention to affect the attitudes or behavior of others, as computers do not have intentions of their own [5]. Several studies show that computer-human persuasion may use some interaction patterns similar to social communication whereas computer-mediated persuasion means that people are persuading others via computers such as e-mail, social network systems, and others [10]. Different frameworks have been existed to support the design of persuasive systems. Lockton [9] introduced the framework 'Design with Intent' (DwI), which clarifies how to use design to modify behavior, and how various persuasive techniques could be applied across domains. The DwI toolkit classified various patterns of persuasive design into eight sets, based on eight different lenses where each lens can influence behavior from a different perspective, for example cognitive, interactive, security, etc. [9].

Fogg Behaviour Model, or "FBM" the short-term, is a model for understanding human behaviors rather than attitudes, which consists of three factors: motivation, ability, and triggers, each of which has subcomponents [5]. It has two axes; the vertical axis is for motivation and the horizontal axis is for ability. These two axes define a plane and there are no units on these two axes; it just shows the relationships of the components rather than accurate values for each, there is a star in the upper right-hand corner that represents the target behavior [5]. A shortcoming of this model is that it does not explain how the principles of suggested design should be transformed into 
software requirements and further implemented as actual features of the system [10].

Another interesting model is the Persuasive Systems Design (PSD) model, which discusses the process of designing and evaluating persuasive systems and consists of three steps of development [10]. The first step is to understand the seven key issues behind persuasive systems before implementing the system [10]. Then, analyze the persuasion context and recognize the intent (the intended change in behaviors and/or attitudes), the event (analyzing the use context, user context, and the technology context), and the strategies (identifying the route that will promote persuasion) for the use of a persuasive system [1]. Finally, design actual system qualities of a new information system or evaluate the features of an existing system that are categorized into four groups: primary task support (facilitating users' interaction with a system), dialogue support (improving dialogue between the user and the system in terms of system's feedback), credibility support (making the design of the system more credible), and social support (increasing user motivation) [10].

\subsection{Persuasive mHealth Apps Design}

The world Health Organization (WHO) has stated that mHealth has "the potential to transform the face of health service delivery across the globe" [12]. Recently, researchers have used mobile phones as tools for encouraging physical activity and healthy diets, for symptoms monitoring in a wide range of diseases, sending reminders to patients about the next appointments, online consultation, etc. [7]. As mHealth applications are gradually becoming a routine way to motivate people toward healthy behavior, the design and functionalities of such apps play a significant role in persuading the public to use those apps. The prospective impact of mHealth apps is dependent on their adaptability to be acceptable to various users [13].

Fogg's framework provides valuable means for understanding persuasive technology, but they seem at a general level specifically for designing and evaluating persuasive systems [10]. Thus, we believe that the persuasive design of mobile health applications launched by the MOH in KSA needs to be examined, using recent persuasive design framework i.e. the PSD model, to achieve the vision of $\mathrm{MOH}$ that focuses on developing healthcare technologies across the Kingdom of Saudi Arabia in terms of quality.

\section{RESEARCH SETTINGS}

\subsection{Evaluation Method}

This study aims to explore, identify and understand the design of $\mathrm{MOH}$ applications by classifying their persuasive features. It also acts as a chance to learn from practice and recognize how different persuasive features have been implemented by mHealth applications and how such implementation could be improved. The methodology used was expert evaluation. The selected experts are specialists in Information Systems with at least seven years of experience in the systems analysis and design field. They evaluated the applications against a checklist of persuasive design principles based on the 28 persuasion features identified by the PSD model [10]. The PSD model was utilized while evaluating mHealth applications because it is comparatively appropriate for designing and evaluating persuasive information systems [8]. The four evaluators separately examined functionalities of the specific applications and compared them against given definitions in the checklist. Each evaluator made notes on an Excel sheet and wrote related comments. They examined the functionalities by reading descriptions of the applications and walking through regular tasks of the Apps. When all four evaluators concluded their evaluation, the recorded comments were reviewed, and a thorough discussion and a synthesis of the findings were made and documented. 
Health Informatics - An International Journal (HIIJ) Vol.9, No.1, February 2020

\subsection{Selecting mHealth Apps}

We aimed to gather a short but representative list of current persuasive features of $\mathrm{MOH}$ applications. Search for mobile health applications published by $\mathrm{MOH}$ was carried out during September 2019 on the iOS and Android platforms using the following search term: "Ministry of Health, Kingdom of Saudi Arabia". The search phrase yields ten hits on the Apple store and Google play. The evaluated applications had to be free of charge and officially published by the Ministry of Health in Saudi Arabia. (See table 1\& 2) for the applications provided and its descriptions.

Table 1.Preliminary survey of MOH Apps by 9-Sep-2019

\begin{tabular}{|c|c|c|c|c|c|c|}
\hline Application Name & \begin{tabular}{|l|} 
User \\
Rating \\
Apple \\
store/ \\
Google \\
play
\end{tabular} & $\begin{array}{l}\text { No. of Rating } \\
\text { Apple store/ } \\
\text { Google } \\
\text { play }\end{array}$ & Category & Target Users & Version & Cost \\
\hline Sehha App & $4.0 / 4.5$ & $948 / 2000$ & Medical & Public & 1.0 .28 & Free \\
\hline Mawid App & $4.1 / 4.7$ & $8.868 / 19000$ & $\begin{array}{l}\text { Health \& } \\
\text { Fitness }\end{array}$ & Public & 10.3 .0 & Free \\
\hline Mawared App & $2.0 / 3.5$ & $1.170 / 1000$ & $\begin{array}{l}\text { Health \& } \\
\text { Fitness }\end{array}$ & $\begin{array}{l}\text { MOH } \\
\text { employees }\end{array}$ & 4.4 & Free \\
\hline $\begin{array}{l}\text { Mystery Shopper } \\
\text { App }\end{array}$ & $3.1 / 4.1$ & $22 / 11$ & Medical & $\begin{array}{l}\text { MOH } \\
\text { employees }\end{array}$ & 3.2 & Free \\
\hline Ashanak App & $2.1 / 2.1$ & $213 / 402$ & Business & $\begin{array}{l}\text { MOH } \\
\text { employees }\end{array}$ & 1.8 & Free \\
\hline $\begin{array}{l}\text { Sehha for Doctors } \\
\text { App }\end{array}$ & $3.6 / 4.2$ & $25 / 58$ & Medical & $\begin{array}{l}\text { MOH } \\
\text { Doctors }\end{array}$ & 1.0 .28 & Free \\
\hline OTARR Easy App & $2.7 / 3.5$ & $3 / 16$ & Medical & Job Candidates & 1.0 & Free \\
\hline Visitors App & $5.0 / 3.5$ & $2 / 11$ & Business & $\begin{array}{l}\text { MOH } \\
\text { Doctors }\end{array}$ & 1.8 & Free \\
\hline Suppliers App & $5.0 / \mathrm{NA}$ & $2 / 0$ & Business & $\begin{array}{l}\text { MOH } \\
\text { Suppliers }\end{array}$ & 2.1 & Free \\
\hline MedConsult App & $5.0 / \mathrm{NA}$ & $2 / 0$ & Medical & $\begin{array}{l}\text { Healthcare } \\
\text { professionals }\end{array}$ & 1.1 & Free \\
\hline
\end{tabular}

Table 2. MOH apps descriptions

\begin{tabular}{|l|l|l|}
\hline $\begin{array}{l}\text { Application } \\
\text { Name }\end{array}$ & Date of Releas & Description \\
\hline Sehha App & $18-3-2017$ & $\begin{array}{l}\text { The user can consult qualified doctors accredited by MOH via } \\
\text { text, voice messages, images and videos. }\end{array}$ \\
\hline Mawid App & $12-10-2017$ & $\begin{array}{l}\text { A mobile app provided by MOH, which enables patients to book } \\
\text { their appointments, cancel or reschedule them. }\end{array}$ \\
\hline Mawared App & $27-11-2017$ & $\begin{array}{l}\text { A mobile app that enables MOH employees to perform their HR } \\
\text { activities in a simple way }\end{array}$ \\
\hline
\end{tabular}


Health Informatics - An International Journal (HIIJ) Vol.9, No.1, February 2020

\begin{tabular}{|l|l|l|}
\hline $\begin{array}{l}\text { Mystery } \\
\text { Shopper App }\end{array}$ & 24-4-2018 & $\begin{array}{l}\text { A mobile app that enables the user to evaluate the offered } \\
\text { services from patients' perspectives to seek improvements for } \\
\text { medical services. }\end{array}$ \\
\hline Ashanak App & $7-10-2017$ & $\begin{array}{l}\text { A mobile app that provides special offers for MOH employees } \\
\text { from different organizations, knowing the latest events of MOH, } \\
\text { internal vacancy jobs and more. }\end{array}$ \\
\hline $\begin{array}{l}\text { Sehha for } \\
\text { Doctors App }\end{array}$ & $18-3-2017$ & $\begin{array}{l}\text { A mobile app that allows accredited doctors to diagnose the } \\
\text { patient via text, voice messages, images and videos. }\end{array}$ \\
\hline $\begin{array}{l}\text { OTARR } \\
\text { Easy App }\end{array}$ & $16-4-2018$ & $\begin{array}{l}\text { A mobile app that enables users to schedule appointments of } \\
\text { Poison \& Control Centre Clinics, know user's request status; } \\
\text { evaluate the offered services and more. }\end{array}$ \\
\hline Visitors App & $3-4-2019$ & $\begin{array}{l}\text { A mobile app which designed for visiting doctors' program } \\
\text { related to the MOH. }\end{array}$ \\
\hline Suppliers App & $26-4-2019$ & $\begin{array}{l}\text { A mobile app that enables the suppliers of MOH to track their } \\
\text { claims and payment status within the ministry. }\end{array}$ \\
\hline $\begin{array}{l}\text { MedConsult } \\
\text { App }\end{array}$ & $28-2-2019$ & $\begin{array}{l}\text { A mobile app that enables healthcare professionals around the } \\
\text { world to connect, consult, share knowledge and provide/receive } \\
\text { advice from each other. }\end{array}$ \\
\hline
\end{tabular}

From the preliminary survey of these applications, it is clear that all of them were published recently between 2017-2019 which means that the MOH is seeking for improving patient care by using information technology and more focused applications that facilitate access to health services from anywhere using smartphones.

The following two criteria were added for further evolution.

- The application should be designed for and accessed by public users.

- The application should require registration.

Based on the abovementioned criteria, we found two well-known applications namely: Sehha and Mawid that satisfied the above criteria. One other application that is not well-known among Saudi Arabia's population called Otarr Easy App has direct access by public users. This app is designed for the job candidates to schedule appointments of Poison \& Control Centre Clinics or know their request status. However, it does not require registration and is only available in three cities of Saudi Arabia, including Dammam, Jeddah, and Al-Qassim. Thus, due to some usage restrictions in this application, it can't be evaluated in this study. Seven of MOH applications were designed for MOH employees, doctors or suppliers as well as for healthcare professionals that can't be accessed by the public users as they have direct access for only those mentioned users.

The two applications that were designed for the public called Sehha and Mawid will be taken into consideration to apply the persuasive technology for the Apps' evaluation. Both Apps available on iOS and Android platforms, they were easy to install and simple to learn. Regarding the registration process, Sehha App was found to be easy whereas Mawid App wasn't easy as it required login via using username and password used for the National Single Sign-On (SSO) portal. 
Health Informatics - An International Journal (HIIJ) Vol.9, No.1, February 2020

\section{RESUltS AND DiSCUSSION}

\subsection{Expert Evaluation Results}

The following tables show expert evaluation for persuasive features applied in the evaluated apps.

Table 3. Primary task support features

\begin{tabular}{|l|l|l|}
\hline Principle & Present in Sehha App & Present in Mawid App \\
\hline \multicolumn{2}{|l|}{ Primary Task Support Category (PTS) } \\
\hline Reduction & $* * * *$ & $* * * *$ \\
\hline Tunnelling & $* * * *$ & $*$ \\
\hline Tailoring & $* * * *$ & $* * * *$ \\
\hline Personalization & $* * * *$ & $* * *$ \\
\hline Self-monitoring & $* * * *$ & $* * * *$ \\
\hline Simulation & No & $* *$ \\
\hline Rehearsal & No & No \\
\hline
\end{tabular}

Table 4. Dialogue support features

\begin{tabular}{|c|c|c|}
\hline Principle & $\begin{array}{l}\text { Present in Sehha } \\
\text { App }\end{array}$ & $\begin{array}{l}\text { Present in Mawid } \\
\text { App }\end{array}$ \\
\hline \multicolumn{3}{|c|}{ Dialogue Support Category (DS) } \\
\hline Praise & $* * * *$ & **** \\
\hline Rewards & No & $*$ \\
\hline Reminders & $* * * *$ & $* * * *$ \\
\hline Suggestion & $* * * *$ & $* * * *$ \\
\hline Similarity & $* * * *$ & $* * * *$ \\
\hline Liking & $* * * *$ & $* * * *$ \\
\hline Social Role & $* * * *$ & No \\
\hline
\end{tabular}

Table 5. System credibility support features

\begin{tabular}{|l|l|l|}
\hline Principle & Present in Sehha App & Present in Mawid App \\
\hline System Credibility Support Category (SCS) \\
\hline Trustworthiness & $* * *$ & $* * *$ \\
\hline Expertise & $* * * *$ & $* * * *$ \\
\hline Surface Credibility & $* * * *$ & $* * * *$ \\
\hline Real World Feel & $* * *$ & $* * *$ \\
\hline Authority & $* * * *$ & $* * *$ \\
\hline Third- Party \\
Endorsements
\end{tabular}


Table 6. Social support features

\begin{tabular}{|l|l|l|}
\hline Principle & $\begin{array}{l}\text { Present in Sehha } \\
\text { App }\end{array}$ & $\begin{array}{l}\text { Present in Mawid } \\
\text { App }\end{array}$ \\
\hline Social Support Category (SS) & \multicolumn{2}{|l|}{} \\
\hline Social Learning & No & No \\
\hline Social Comparison & No & No \\
\hline $\begin{array}{l}\text { Normative } \\
\text { Influence }\end{array}$ & No & No \\
\hline Social Facilitation & No & No \\
\hline Cooperation & No & No \\
\hline Competition & No & No \\
\hline Recognition & $* * *$ & $* * *$ \\
\hline
\end{tabular}

\subsection{Persuasion Context \& Features Discussion}

According to the PSD model, the initial step is to identify a persuasion context for the selected mHealth applications. This context includes recognizing the persuasion intent, understanding the event of persuasion, and defining the strategies in use. Based on the evaluated apps, the following PSD context was highlighted.

The Intent: it is clear that the main persuader for Sehha and Mawid Apps is the Saudi Ministry of Health i.e. the developer of the applications. The intention of the developer was not clearly specified in Mawid App but it was visibly defined in Sehha App description, which states that "The app is built for humanitarian and confidential service to enhance communication between patients and physicians and to facilitate direct medical consultation on mobile phones and support the health decisions that patients can make about their health".

The Event: The event is about understanding the user, technology and the use context. Based on the Sehha App's description, we found that the app was designed for people who wish to save time and/or effort, conduct online consultation and get telemedicine from anywhere and anytime. It was not designed for children under the age of 13. Registered adult users of this app can use it for the benefit of children. Therefore, Sehha App is used for personal, not for commercial purposes; Organizations, businesses, and companies may not become registered members or use the app as entities or through individual members. About Mawid App, based on its description in the apple store and google play, we found that the app was designed to enable patients to book their appointments across primary healthcare centers (PHC) and manage them by rescheduling or canceling their appointments as well managing their referral appointments.

The Strategy: The PSD model identifies two key elements as possible strategies for persuading users, i.e. the message and the route. The routes may be direct (using logical argument), indirect (using cues) or a mix of both, depending on the user's ability to evaluate the content of the persuasive message [8]. It is clear that Sehha App uses unobtrusive persuasive technologies; it stated the persuasion intent and the type of change being targeted in the App's description. So, we assume it is targeting both changes in behavior and attitude, i.e. it aims to persuade the user to use technology and do online consultation as well to be loyal to the application. On the other hand, Mawid App did not state the intent and the type of change obviously in the app as there was no clear description presented in the app. However, through using the App we suggest that it is targeting both changes in behavior and attitude, i.e. it aims to persuade the patients to be organized and do online booking for their appointments in advance and to be faithful to the application. 


\subsection{Persuasive Features}

It is widely accepted that the use of the PSD model helps us to identify precise persuasive features for application's qualities that promote persuasive interactions. We demonstrate the feasibility of this model by discussing the described functionalities belong to the four different categories. Briefly, the results disclose extensive use of persuasive features; especially those related to credibility support, dialogue support, and primary task support. However, the evaluated applications lacked features related to social support, thus there is a need for improvement in designing and incorporating social persuasive techniques in $\mathrm{MOH}$ applications.

\subsection{Primary Task Support}

The primary task is the main task or activity the application is designed to support, i.e. the Sehha App supports the user's primary task of conducting an online consultation with one-click only whereas Mawid App supports the user's primary task of booking and managing appointments online. The analysis denoted that all primary task features were utilized, except simulation and rehearsal features. Reduction, tunneling, tailoring, personalization, and self-monitoring appeared to be the most applied features (See table 3).

It was clear that Sehha App reduced the time spent in the traditional way for consulting doctors with only one click consultation using their smartphones and mHealth app. It was found that the app leveraged the principle of tunneling by enabling users to freely register and create an account to start an online consultation. The tailoring principle was utilized by providing tailor information based on users' potential interests; as Sehha App designed for individuals (patients), the information presented in this app was found completely related to patients only not for doctors. Also, the principle of personalization was used by enabling the adding of an individual's name, age, gender and contact information, hence the medical case can be forwarded to the appropriate doctor based on user-inputs. Self- monitoring was utilized by providing a means to track the running information, reviewing previous history or previous consultations.

On the other hand, the reduction principle in Mawid App was identified which reduced the waiting time spent in the PHC by allowing patients to book and manage their appointments in advance. However, it seemed that the tunneling principle in this App was underutilized as it required users to login via using their usernames and passwords used for the National Single Sign-On (SSO) portal which sometimes considered time-consuming for patients. But in the latest version, two options keep login process easier: Remember me and/or use a fingerprint. The tailoring feature was used by providing tailor information based on users' interests and usage context, hence the information presented in this app was completely related to patients or their dependents only. The App leveraged the personalization feature by offering personalized content based on users' input. Self- monitoring principle was utilized by allowing users to review previous or upcoming booking history. Simulation feature was found in the app that provided means for observing the link between cause and effect e.g. displaying the nearest PHC based on patients' location. Finally, it has been noticed that 5 out of 7 features were visibly incorporated in both evaluated applications.

An essential persuasive feature, the rehearsal, was underutilized in the applications in addition to the simulation feature in Sehha App.

\subsection{Dialogue Support}

Dialogue support features were moderately used, integrating features that support dialogue between the user and the online physician. In Sehha App, the analysis indicated that all dialogue support features were utilized, i.e. praise, reminders, suggestions, similarity, liking and social role 
except for the rewards feature. The app used the praise features, i.e. giving positive verbal feedback after registration or after evaluating the services, e.g. 'Congratulations, you have successfully registered'. Reminders were employed in different forms, such as the notification about an upcoming-booked appointment or the doctor's acceptance and closing of the consultation. The suggestions came in the form of suggesting the nearest available appointment for booking a consultation with virtual doctors. The similarity was utilized by imitating users via using their language, names, etc. In addition, the liking feature was appeared in the design of this app by using a user-friendly interface, convenient colors, etc. Finally, the Sehha app adopted a social role feature, e.g. automated online assistance, which in our case was the virtual doctor in which users can chat with to discuss related issues.

Regarding Mawid App, the analysis showed that most of the dialogue support features were employed, i.e. praise, reminders, suggestions, similarity, liking except for rewards and social role features. The praise feature was used by giving positive verbal feedback after registration, booking an appointment or evaluating the services, e.g. 'Your appointment was created successfully'. Reminders were found to be the most common feature to enhance the user-system dialogue in this App, e.g. the reminding notification sent for an upcoming-booked appointment through an email or SMS. Suggestions feature was incorporated in a form of suggesting the nearest available appointment or the nearest PHC. The similarity was identified as the persuasive feature that imitating users by using their languages, names, etc. The use of the liking feature was utilized in the design of this app using the user-friendly interface, likable colors, etc. Social role feature was found to be absent from the evaluated applications. We can conclude that most of the components of the dialogue support were utilized as 5 out of 7 features were clearly applied in the evaluated applications (See table 4).

\subsection{Credibility Support}

Credibility has a significant influence on the persuasion of mHealth applications. Based on the evaluations, we suggest that both applications indicated a high level of credibility. It would appear that the Sehha App has a sensible credibility. All credibility features including trustworthiness, expertise, surface credibility, real-world feel, authority, third party endorsements, and verifiability were implemented. Regarding the trustworthiness feature, it was found that the app provided truthful, fair and unbiased information, e.g. the app stated the privacy of sensitive information. The expertise feature was presented in the app that offers information showing knowledge, experience, and competence of the ministry of health. About the surface credibility feature, it was found that the app had competent look and feel e.g. the design reflected the context. The realworld feel feature was employed to increase the app's credibility by providing information about the Ministry of Health and contact details for sending feedback and complaints. The authority feature, i.e. providing a means to verify the accuracy of the app's content, e.g. quoting authority statements from the authorized organization i.e. Saudi Ministry of Health. The third-party endorsements feature was mentioned in the app, showing that this app did not have editorial control over or responsibility for content provided by third-parties such as medical experts. Finally, the verifiability feature was applied, e.g. verification number for Sehha App sent via SMS to the users' phones when they register.

By referring to Mawid App, we found that most of the credibility features were utilized. It was identified that the trustworthiness feature was employed as the app required registration via using National SSO portal. The expertise feature was presented in the app that showed the contact number of default PHC and whether it opened or closed at the time of booking an appointment. Concerning the surface credibility feature, it was found that the application had an appropriate look and feel. The real-world feel feature was found to increase the app's credibility by providing a non-dangling link via SM 
$\mathrm{S}$ or Email to send users' feedback or app's evaluation. Authority feature was utilized which providing a means to verify the accuracy of the app's content through using the National SSO account to login and showing the official website link on the homepage of the app. The thirdparty endorsements were not presented in the App. Lastly, the verifiability feature was found in the app, e.g. verification number for Mawid App sent via SMS to the users' phones when they register. To conclude, credibility support features were the most highly used features in both applications included in this study as 6 out of 7 credibility persuasive features were visibly utilized (See table 5).

\subsection{Social Task Support}

Social support was the least common category utilized in the evaluated applications (See table 6). In this study, recognition was the only common social support feature that applied to both apps. For Sehha App, it was found that a recognition message was sent to the user who performed the target behavior e.g. sending thanks message after using the app and asking for rating the experience with the doctor who provided the consultation to the patient since patient's opinion is very important to improve the medical services. Regarding Mawid App, similar to Sehha App, it was identified that a recognition message was sent via SMS to the user who performed the target behavior e.g. sending thanks message after attending the appointment and asking for rating the services provided by the PHC, doctor, and pharmacy to improve MOH services. To sum up, the degree of social support features in the evaluated applications was found to be minimal and necessitated an improvement in the next updates for the two apps. The summary of the applied features in both apps (Sehha and Mawid) are presented in the following figure.

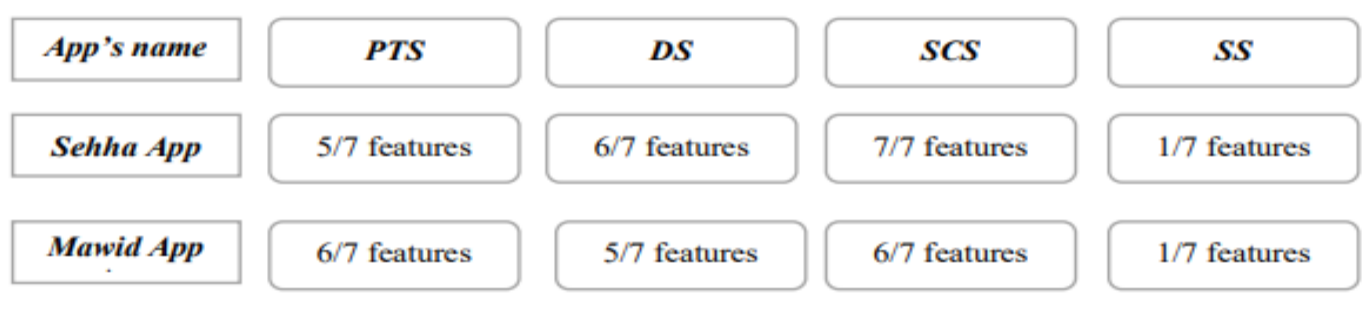

Figure 1. Applied PSD features in the evaluated apps

\subsection{Recommendation for Improvement}

Based on the results of this study, it is clear that there is a need for improvement in designing and implementing persuasive features for mobile applications published by $\mathrm{MOH}$ with a great effort on social support features. For Sehha App, some persuasive features should be added in the next coming updates. For instance, using artificial intelligence to employ simulation feature in the app that can help in providing an automated medical diagnosis. Utilizing rehearsal feature would also strengthen the primary task support principle. Applying rewards feature will persuade users to use the app frequently. In addition, the success of the app would be increased through enhanced social persuasive features e.g. allowing users to share their experience with others.

In the same way, applying more persuasive features for Mawid App will enrich users' individual motivation to perform the target behavior. For example, displaying a short video to clarify how to use the app would provide a means for rehearsing the target behavior. Offering some rewards and adding chatbot features will boost the dialogue support category. Moreover, adding some information about the app and the terms and conditions would increase the credibility of the app. Finally, an extensive effort is needed for applying social features to increase the persuasiveness of the app. The persuasive design recommendations for Sehha and Mawid Apps are described in the following table (See table 7). 
Health Informatics - An International Journal (HIIJ) Vol.9, No.1, February 2020

Table 7. Recommendation for improving the evaluated apps

\begin{tabular}{|c|c|c|c|}
\hline Principle & $\begin{array}{c}\text { Persuasive } \\
\text { Design Feature }\end{array}$ & $\begin{array}{c}\text { Design Recommendation for } \\
\text { Sehha App }\end{array}$ & $\begin{array}{l}\text { Design Recommendation for } \\
\text { Mawid App }\end{array}$ \\
\hline PTS & Simulation & $\begin{array}{l}\text { Provide means for observing } \\
\text { the link between cause and } \\
\text { effect } \\
\text { e.g. providing automated } \\
\text { diagnostic \& medical } \\
\text { guidance services, based on } \\
\text { patient's health } \\
\text { condition. }\end{array}$ & - \\
\hline PTS & Rehearsal & $\begin{array}{l}\text { Provide means for rehearsing } \\
\text { a target behaviour e.g. short } \\
\text { video clarifying how to use } \\
\text { the App. }\end{array}$ & $\begin{array}{l}\text { Provides means } \begin{array}{l}\text { for } \\
\text { rehearsing } \\
\text { behaviour }\end{array} \text { e.g. short video } \\
\text { clarifying how to use the } \\
\text { App. }\end{array}$ \\
\hline $\mathrm{DS}$ & Rewards & $\begin{array}{l}\text { Increase the number of } \\
\text { allowed consultations for } \\
\text { each user from the fixed } \\
\text { number ( } 3 \text { times per month) } \\
\text { to more than } 5 \text { to } \\
10 \text { consultations, based on } \\
\text { his/her situation }\end{array}$ & $\begin{array}{l}\text { Offer discount voucher for } \\
\text { buying medicine, by } \\
\text { cooperating with some } \\
\text { pharmacies, for users who } \\
\text { use and book their } \\
\text { appointments through the } \\
\text { App. }\end{array}$ \\
\hline $\mathrm{DS}$ & Social Role & - & $\begin{array}{l}\text { Adopt social role e.g. } \\
\text { chatbot to answer simple } \\
\text { queries from users. }\end{array}$ \\
\hline SCS & $\begin{array}{c}\text { Third- Party } \\
\text { Endorsements }\end{array}$ & 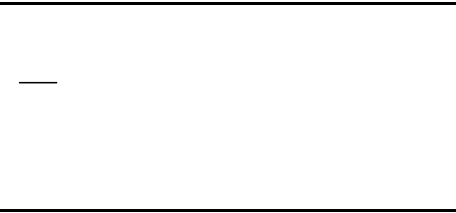 & $\begin{array}{l}\text { Add (About us) feature in } \\
\text { the App including } \\
\text { information about the App, } \\
\text { terms and conditions, } \\
\text { privacy policy, support etc. }\end{array}$ \\
\hline SS & Social Learning & $\begin{array}{l}\text { Add a review board to allow } \\
\text { users to observe other's } \\
\text { behaviours \& outcomes } \\
\text { e.g.users } \\
\text { review board showing what } \\
\text { other users are experiencing } \\
\text { about the App or other } \\
\text { medical } \\
\text { concerns. }\end{array}$ & $\begin{array}{l}\text { Add a review board to allow } \\
\text { users to observe } \\
\quad \text { other's } \\
\text { behaviours \& outcomes e.g. } \\
\text { users review board showing } \\
\text { what other users are } \\
\text { experiencing about the } \\
\text { App, PHC or other medical } \\
\text { issues. }\end{array}$ \\
\hline SS & $\begin{array}{c}\text { Social } \\
\text { Comparison }\end{array}$ & $\begin{array}{l}\text { Allow users to compare own } \\
\text { performance with others e.g. } \\
\text { sharing \& comparing info } \\
\text { with others via review board } \\
\text { or instant message. }\end{array}$ & $\begin{array}{l}\text { Allow users to compare } \\
\text { own performance with } \\
\text { others e.g. sharing \& } \\
\text { comparing info with others } \\
\text { via review board or instant } \\
\text { message. }\end{array}$ \\
\hline SS & $\begin{array}{l}\text { Normative } \\
\text { Influence }\end{array}$ & $\begin{array}{l}\text { Provide means for gathering } \\
\text { people together who have the } \\
\text { same goal \& makes them feel } \\
\text { norms } \\
\text { e.g. showing pictures of new- } \\
\text { born babies with serious health } \\
\text { problem due to mum's } \\
\text { smoking. }\end{array}$ & $\begin{array}{l}\text { Provide means for } \\
\text { gathering people together } \\
\text { who have the same goal \& } \\
\text { makes them feel norms e.g. } \\
\text { showing others reviews } \\
\text { about specific PHC. }\end{array}$ \\
\hline
\end{tabular}


Health Informatics - An International Journal (HIIJ) Vol.9, No.1, February 2020

\begin{tabular}{|c|l|l|l|}
\hline SS & Social Facilitation & $\begin{array}{l}\text { Allow users to discern others } \\
\text { performing the same behaviour } \\
\text { along with them e.g. How } \\
\text { many users using the app right } \\
\text { now? }\end{array}$ & $\begin{array}{l}\text { Allow users to discern others } \\
\text { performing the same } \\
\text { behaviour along with them } \\
\text { e.g. How many users booking } \\
\text { appointments with the same } \\
\text { PHC for today? }\end{array}$ \\
\hline SS & Cooperation & $\begin{array}{l}\text { Allow users to cooperate } \\
\text { e.g. user review board }\end{array}$ & $\begin{array}{l}\text { Allow users to cooperate } \\
\text { e.g. user review board }\end{array}$ \\
\hline SS & Competition & $\begin{array}{l}\text { Provide means for competing } \\
\text { with others } \\
\text { e.g. share \& get (share the app } \\
\text { for more than 5 people \& get } \\
\text { extra consultations per month) }\end{array}$ & $\begin{array}{l}\text { Provide means for competing } \\
\text { with others e.g. book \& win } \\
\text { book an appointment } \\
\text { through the app \& win } \\
\text { purchasing voucher for } \\
\text { medication) }\end{array}$ \\
\hline
\end{tabular}

\section{Conclusions}

This paper presents findings from the evaluation of persuasive features in mHealth apps developed by the $\mathrm{MOH}$ in KSA accessed by the public users. It categorizes various persuasive features from the evaluated applications. Besides, it suggests some recommendations to improve the persuasion of the evaluated apps among public users. One of the limitations of this study is small sample sizes as we cannot have direct access to all applications of $\mathrm{MOH}$. Thus, the results may not be generalizable to other MOH apps. However, the main two applications that are very popular amongst the population have been evaluated based on persuasive technology. This, in turn, will give a great insight for the developers and researchers to understand the requirements and demands of KSA users. In addition, expert evaluations have some limitations, for example, the possibility of bias. However, we have tried to get under control of such limitations by having four evaluators.

Regarding the PSD model, it was found out that some of the social support principles are somewhat ambiguous and overlapping. It was noticed in this research the link between social learning, social facilitation, normative influence social comparison and cooperation features are hard to distinguish from each other. Moreover, since the PSD model contains a total of 28 persuasive design principles, the evaluation of applications may be quite exhausting and timeconsuming. However, it was demonstrated that the PSD model is feasible for evaluating the design specifications of apps and was easy to walk through its principles.

\section{ACKNOWLEDGEMENTS}

The author would like to thank Dr. Abdul Rauf Baig for his guidance and the expert evaluators who participated in this study.

\section{REFERENCES}

[1] M. Alhammad and S. Gulliver, "ONLINE PERSUASION FOR E-COMMERCE WEBSITES", In Proceedings of the 28th International BCS Human Computer Interaction Conference on HCI 2014Sand, Sea and Sky-Holiday HCI. BCS. pp. 264-269.

[2] C. Aranda-Jan, N. Mohutsiwa-Dibe and S. Loukanova, "Systematic review on what works, what does not work and why of implementation of mobile health (mHealth) projects in Africa", BMC Public Health, vol. 14, no. 1, 2014. 
Health Informatics - An International Journal (HIIJ) Vol.9, No.1, February 2020

[3] P. Briñol and R. Petty, "Persuasion: Insights from the self-validation hypothesis", Advances in experimental social psychology, vol. 41, pp. 69-118, 2009.

[4] S. Consolvo, P. Klasnja, W. McDonald, D. Avrahami, J.Froehlich, L. LeGrand, ... \& J. Landay, "Flowers or a robot army?: encouraging awareness \& activity with personal, mobile displays," In Proceedings of the 10th international conference on Ubiquitous computing, 2008, pp. 54-63.

[5] B. Fogg, "A behavior model for persuasive design" , In Proceedings of the 4th international Conference on Persuasive Technology, 2009, p. 40.

[6] X. Gu, X. Yang, H. Li, Jain and C. Liang, "Understanding the Role of Mobile Internet-Based Health Services on Patient Satisfaction and Word- of-Mouth", International Journal of Environmental Research and Public Health, vol. 15, no. 9, p. 1972, 2018.

[7] P. Klasnja and W. Pratt, "Healthcare in the pocket: Mapping the space of mobile-phone health interventions", Journal of Biomedical Informatics, vol. 45, no. 1, pp. 184-198, 2012.

[8] S. Langrial, T. Lehto, H. Oinas-Kukkonen, M. Harjumaa, \& P. Karppinen, "Native Mobile Applications for Personal Well-Being: A Persuasive Systems Design Evaluation”, In PACIS, 2012, p. 93.

[9] D. Lockton, D. Harrison and N. Stanton, "The Design with Intent Method: A design tool for influencing user behaviour", Applied Ergonomics, vol. 41, no. 3, pp. 382-392, 2010.

[10] H. Oinas-Kukkonen, "Persuasive Systems Design: Key Issues, Process Model, and System Features", Communications of the Association for Information Systems, vol. 24, 2009.

[11] T. Räisänen, T. Lehto and H. Oinas-Kukkonen, "Practical Findings from Applying the PSD Model for Evaluating Software Design Specifications", Persuasive Technology, pp. 185-192, 2010. Available: 10.1007/978-3-642-13226-1_19 [Accessed 8 November 2019].

[12] WHO Global Observatory for eHealth (2011) New horizons for health through mobile technologies. Geneva: World Health Organization. available: http://www.who.int/goe/publications/ehealth_series_vol3/en/

[13] A. M.Mostafa, A. E.Youssef and G. Alshorbag, "A Framework for a Smart Social Blood Donation System Based on Mobile Cloud Computing", Health Informatics - An International Journal, vol. 3, no. 4, pp. 1-10, 2014. Available: 10.5121/hiij.2014.3401 [Accessed 3 December 2019].

[14] R. Hasanain, K. Vallmuur and M. Clark, "Progress and Challenges in the Implementation of Electronic Medical Records in Saudi Arabia: A Systematic Review", Health Informatics - An International Journal, vol. 3, no. 2, pp. 1-14, 2014. Available: 10.5121/hiij.2014.3201 [Accessed 3 December 2019].

\section{AUTHOR}

Asmaa Shati is a student of MSc (Information Systems) in University of IMSIU. She is working as a Teaching Assistant, Department of Information Systems, University of KKU, KSA. Her research of interest includes Human Computer Interaction, System Analysis and Design, Persuasion Technology and Mobile Computing 